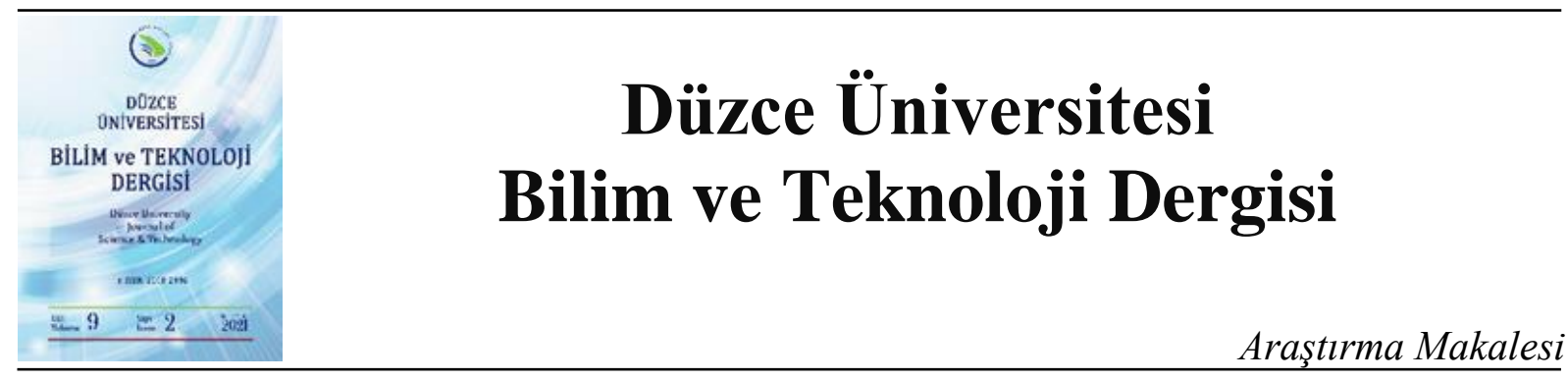

\title{
Otellerde İç Mekân Bitki Tercihlerinin Bitkisel Tasarım İlkeleri Kapsamında Değerlendirilmesi ve Bakım Olanaklarının Belirlenmesi: Antalya Örneği
}

\author{
Ceren SELIM ${ }^{\mathrm{a}, *}$ \\ ${ }^{a}$ Peyzaj Mimarlı̆̆ı Bölümü, Mimarllk Fakültesi, Akdeniz Üniversitesi, Antalya, TÜRKIYE \\ * Sorumlu yazarin e-posta adresi: cerenselim@akdeniz.edu.tr
}

DOI: $10.29130 /$ dubited.872113

\begin{abstract}
ÖZET
$\mathrm{Bu}$ çalışmada, Antalya ilinde yer alan beş yıldızlı otellerin iç mekânlarında kullanılan bitki türü tercihlerinin, bitkisel tasarım kriterleri açısından değerlendirilmesi ve bakım uygulamalarının belirlenmesi amaçlanmıştır. Bu kapsamda Türkiye'nin en önemli turizm destinasyonlarının başında gelen Antalya İlinde bulunan yirmi otelde yer alan iç mekan bitkileri, yerinde yapılan gözlemler ve sorumlu departmanlarla yapılan görüşmeler ile işlevleri, bakım uygulamaları, bitkisel tasarım öğeleri ve ilkeleri açısından değerlendirilmiştir. Elde edilen bulgular, ekonomik kaygılar ve bakım zorluklarından dolayı tercih edilen iç mekan bitkisi seçiminde genellikle az bakım isteyen ve ekonomik bitkilerin seçildiğini göstermiştir. Ayrıca bitkilerin estetik özelikleri ve vurgu yapma işlevleri nedeniyle bitkisel tasarımlarda yer bulurken, hava kalitesini iyileştirme, insan psikolojisine olumlu katkı sağlama, iş verimini artırma, sınırlama ve yönlendirme işlevlerinin nispeten ön plana çıkmadığı belirlenmiştir.
\end{abstract}

Anahtar Kelimeler: İ̧ mekân bitkileri, Süs bitkileri, Otel, Bitkisel tasarım, Peyzaj bakımı

\section{Evaluation of Indoor Plant Preferences in Hotels within the Scope of Planting Design Principles and Determination of Maintenance Possibilities: The Case of Antalya}

\begin{abstract}
In this study, it was aimed to evaluate the plant species preferences in the interiors of five-star hotels in Antalya in terms of plant design criteria and to determine the maintenance practices. In this context, indoor plants preferences, functions, maintenance practices were evaluated in terms of plant design elements and principles in twenty fivestar hotels which were located in Turkey's most important tourism district of Antalya province coastal zone. According to the findings, economic concerns and maintenance difficulties have shown that low-maintenance and economical plants are generally chosen in the selection of indoor plants preferred in hotels. In addition, it has been understood that while plants find a place in planting designs due to their aesthetic features and their emphasis functions, the functions of improving air quality, contributing positively to human psychology, increasing work efficiency, restricting, directing functions were ignored.
\end{abstract}

Keywords: Indoor plants, Ornamental plants, Hotel, Planting design, Landscape management

Geliş: 01/02/2021, Düzeltme: 14/02/2021, Kabul: 18/02/2021 


\section{GİRIS}

Hızlı nüfus artışına paralel olarak artan konut ihtiyacı özellikle kentsel yerleşimlerde betonlaşmayı arttırmakta ve bu durum yeşil doku üzerinde önemli bask1 oluşturmaktadır. İnsanoğlunun doğadan uzaklaşmasının sebeplerinden biri olan bu kentleşme süreci ekolojik, estetik, ekonomik ve sosyal olarak birçok fonksiyonu olduğu bilinen yeşil doku varlığının kentlerde yaşanan arazi rantına bağlı olarak yapılar arasında sıkışmasına sebebiyet vermektedir. Günlük yaşantısının \%80-90'ını iç mekanlarda geçiren insanoğlu bilgi teknolojilerinin de gelişmesiyle, bilgisayarlara ve iç mekanlara mahkûm kalmaktadır. Bununla birlikte, bilgi teknolojisinin bu denli hızlı yayılımı, yeni bilgisayar teknolojileriyle sağlıklı bir şekilde baş edememenin neden olduğu modern bir hastalık olan "Teknostres" gibi farklı stres faktörlerinin hayatımıza nüfuz etmesine neden olmuştur [1,2]. Yoğun ve sıkışık kent dokusu içerisinde doğaya ve yeşile mahrum kalan insanlar, yeşil dokuya yaşamlarının büyük bir kısmını geçirdikleri yapı blokları içerisinde yer vererek iç mekân bitkilerini kullanmaya başlamışlardır. Yazılı belgeler, bitkilerin iç mekânda kullanımının ilk örneklerini Mısır yazıtlarında ve Pompei kentinde günümüzden yaklaşık 2000 yıl öncesinde kullanılmaya başlandığını göstermiştir [3,4]. Tropikal ve subtropikal bitkiler için daha düşük nakliye ve üretim maliyetleri, iç mekân tasarım uygulamalarındaki farklılıklar ve bitkileri iç mekânda tutmayı mümkün kılan daha yüksek iç mekân sıcaklıklarının sağlanabilmesinden dolayı 20. yüzyılın ikinci yarısında iç mekan bitkilerinin kullanımı daha da yaygınlaşmıştır [4]. Bitkilerin, dış mekândan iç mekâna taşınmasıyla doğanın pozitif enerjisi iç mekânlara yansımaya başlamış, bu da insanların iç mekânlarda kendilerini daha mutlu, huzurlu ve konforlu hissetmelerine olanak sağlamıştır [5]. İç mekânda yapılan bir bitkisel tasarım faaliyeti ile bitkilerin doku, renk, çizgi, ölçü, form vb. gibi tasarımsal özelliklerinden faydalanarak cazip mekanlar yaratmak mümkündür. Cansız elemanların yerine getireceği bazı fonksiyonları, canlı eleman olan bitkilerle yerine getirmek, doğal peyzajın, kapalı mekanlarda sürdürülebilirliğini sağlamaktadır [6]. Çelem ve Arslan [7] iç mekân bitkisi yetiştiren kişilerin kendilerini daha huzurlu ve rahat hissettiklerini belirtmişlerdir. Sürekli değişim halinde olan iç mekân bitkileri çağdaş dünyada insanlara doğa ile ilişki olanağı sunan canlı varlıklar olarak tanımlanmaktadır [8]. Günümüzde dünyanın her yerinde insanlar bitkileri evlerine, iş yerlerine, alışveriş merkezlerine, restoranlara, otellere ve günlük yaşamın diğer ortamlarına taşımışlardır [4].

Doğa ile etkileşim hem yaşam kalitesini artırmak hem de insanlara psikolojik faydalar ve bilişsel performans dahil olmak üzere bir dizi ölçülebilir fayda sağlamak açısından önemlidir [9]. Doğayla bağlantı kurmamızı sağlayan ve hayatımızı renklendiren iç mekân bitkileri birçok estetik, fizyolojik ve psikolojik fayda sağlamaktadır. İç mekân bitkileri, üç boyutlu çevrenin bir parçası olmakta ve birçok yönden insanla etkileşime girmektedir [9]. Bitkiler tarafından gerçekleştirilen fotosentez ve terleme süreçleri bitkiler için önemli süreçlerdir [10]. Fotosentez, bitkilerin karbondioksiti $\left(\mathrm{CO}_{2}\right)$, 1şığı ve suyu enerjiye dönüştürdüğü ve yan ürün olarak oksijeni $\left(\mathrm{O}_{2}\right)$ serbest bıraktığı bir süreçtir. $\mathrm{O}_{2}$, diğer organizmaların gelişmesi için gereklidir ve bu süreçler dünyanın karbon ve oksijen döngülerini oluşturur [11]. Fotosentez sırasında üretilen negatif hava iyonları insanların sağlığı için faydalıdır [12]. Terleme ise, suyun bitki köklerinden yapraklarına geçerek su buharına dönüştüğ̈̈ ve atmosfere salındığı bir süreçtir. Bitkilerin bu özelliği, bulundukları ortamdaki nemin düzenlenmesine imkân sağlar [13]. Ayrıca bitkilerinin havayı filtreleme özelliğinden dolayı bulundukları ortamın hava kalitesini arttırarak insan sağlığını olumlu etkilediği [13-20] ve termal konfor sağladığını [21] kanıtlayan birçok araştırma mevcuttur. Bu bağlamda iç mekânda bitkileri kullanarak kirleticilerin ortadan kaldırılması etkili ve ekonomik bir strateji olmakla beraber fizyolojik açıdan da oldukça önemlidir.

İç mekân bitkileri, yalnızca iç mekân hava kirleticilerinin ortadan kaldırılmasında önemli bir rol oynamakla kalmaz, aynı zamanda ortamın iyileştirilmesine, bireyler üzerinde olumlu psikolojik etki sağlayarak stresi azaltma, sağlık ve konforu olumlu yönde teşvik etmeye katkıda bulunur [4,9,22-25]. İç mekân bitkilerinin insanı dinç hissettirdiği, iş verimliliğini arttırdığg ve psikolojik olarak insan sağlığına iyi geldiği yapılan çalışmalarla kanıtlanmıştır. Özellikle ofislerde çalışanların iş verimini arttırdığ $[23,26]$, okullarda öğrencilerin daha motive olmasına, çalışanların dikkat ve performansları üzerine katkıda bulunduğu ve mekândaki aidiyet ve mutluluk duygularına katkı sağladığı [13,27-34], hastanelerde hastalık semptomlarının azalmasına etki ettiği ve iyileşmeyi çabuklaştırdığı belirtilmiştir [35-37]. İç mekân bitkileri aynı zamanda estetik açıdan iç mekâna katkı sağlayarak, kimlik kazandırır. 
Bitkiler sahip oldukları yaprak, çiçek gibi özellikleri ile yaşanabilir ve estetik mekânlar oluşturulmasına katkı sağlamaktadır [8,38]. Bitkiler bu katkıyı, diğer bitkilerle oluşturdukları kompozisyonlar ve mekânı oluşturan diğer öğeler ile sahip oldukları tasarım öğelerini ile (form, çizgi, doku, renk, ölçü) "bitkisel tasarım kriterleri” doğrultusunda gerçekleştirebilirler. İç mekânda gerçekleştirilecek bir bitkisel tasarım faaliyetini; mekânın özellikleri, kullanıcı istekleri ve beklentileri, bitkilerin ekolojik istekleri ve tasarımcının tercihleri şekillendirir [39]. Dolayısıyla bitkisel tasarım öncesinde mekân analizi yapılmalı, mekânın işlevi, kullanım durumu, yoğunluğu, fiziksel özellikleri ve ekolojik koşullar irdelenmelidir. Mekân kullanıcılarının mekânla ilgili istekleri, kullanıcı tipi, yoğunluğu, zevkleri gibi psikolojik, fizyolojik ve sosyolojik gereksinimleri belirlenmelidir. Bitkisel tasarım faaliyetinde kullanılacak bitkilerin ekolojik istekleri, renk, doku, form, ölçü, biçim gibi tasarımsal öğelerin bilinmesi ve iç mekânda var olan diğer cansız öğeler ile ilişkilerin dikkate alınması gerekir [39]. Tasarım tasarımcıya göre değişiklik göstermekle birlikte özgün yaklaşım, bakış açısı vb. etmenlere bağlı olarak algıda farklılığı yaratabilir, kullanıcı üzerinde farklı hisler uyandırabilir. Bitkisel tasarım ilkeleri doğrultusunda yapılacak bitkisel tasarımlarda; vurgu-odak, ritim-tekrar, denge, egemenlik, oran, birlik, uyum-zitlık ve koram-hiyerarşi oluşturma imkânı sunar. Örneğin; kapalı ve alçak bir mekânı bitkilerin renk, form, ölçü ve çizgi özelliklerinden yararlanarak daha geniş ve yüksek hissettirebilir veya geniş ve yüksek bir mekânı insan ölçeğine indirgeyebilir. Yüksek tavanlı yapılarda (havalimanları, alış-veriş merkezleri, otel lobileri vb.) gerçekleştirilen iç mekân bitkisel tasarımlarında oran, denge ve hiyerarşi gibi tasarım öğeleri kullanılarak bitki materyali ile mekânlar insan ölçeğine indirgenebilir, mekânın insan üzerinden yarattığı baskı ve psikolojik etki olumlu yönde iyileştirilebilir. Bunun yanında bitkilerin ekolojik istekleri, bakım gereklilikleri, saksı tercihleri, işlevsellik, mekâna uyum, amaca uygunluk, doğal/egzotik tür tercihleri ve ekonomik koşullar bitkisel tasarımda düşünülmesi gereken diğer hususlardır.

İç mekân bitkilerinin kendilerinden beklenen faydaları sağlayabilmeleri, sağlıklı bir şekilde gelişebilmeleri mekâna uygun tür seçimine, türlerin ekolojik isteklerinin (1ş1k, sıcaklık, nem ve su, yetiştirme ortamı) karşılanmasına ve bu isteklere uygun bakım uygulamalarının (sulama, gübreleme, saksı değiştirme, yabancı ot kontrolü, kurumuş dal ve yaprakların temizliği, hastalık ve zararlılarla mücadele) yapılmasına bağlıdır [5,8,40]. İç mekân bitkilerinin büyüme ve gelişmesini etkileyen ekolojik faktörlerin başında sıcaklık gelmektedir. İç mekân bitkilerinin tümü için uygun olan bir sıcaklık derecesi olmamakla birlikte, genel olarak $0-40^{\circ} \mathrm{C}$ arasında değişiklik gösterir. Uygun sıcaklık, bitkilerin doğal yetişme koşullarına, mevsime göre değişmekle birlikte iç mekân bitkilerini sıcaklık gereksinimlerine göre düşük, orta ve yüksek sıcaklık isteği olan bitkiler olmak üzere üç gruba ayırabiliriz. Örneğin; Anthurium andraeanum (Antoryum), Dieffenbachia maculata (Difenbahya), Dracaena spp. türleri yüksek sıcaklığa (Kışın:16-20 ${ }^{\circ} \mathrm{C}$, Yazın:18-25 ${ }^{\circ} \mathrm{C}$ ) ihtiyaç duyarken, Begonia rex. (Yaprak Güzeli Begonya), Ficus spp., Euphorbia pulcherrima (Atatürk çiçeği) türleri orta sıcaklık (Kışın:8-15 ${ }^{\circ} \mathrm{C}$, Yazın:15-18 ${ }^{\circ} \mathrm{C}$ ) isteğine ihtiyaç duymaktadır. Agave spp. (Sart sabır), Fatsia japonica (Japon aralyasl), Echeveria spp.türleri ise düşük sıcaklık (Kışın:5-8 ${ }^{\circ} \mathrm{C}$, Yazın:15-20 $\left.{ }^{\circ} \mathrm{C}\right)$ isteğine sahiptir. İç mekân bitkilerinin ekolojik gereksinimlerinden bir diğeri 1şıtır. Işık, bitkilerde fotosentezi etkileyerek bitkilerin büyüme ve gelişmesini direk olarak etkilemektedir. Bu bakımdan iç mekân bitkilerinin bazıları sürekli ışı isteği olan bitkilerdir (örn. Kaktüs ve Sukkulent türleri). Bu gruba giren bitkileri konumlandırırken güney cephelerde, 1şık alabilecek pencere kenarlarını tercih edilmelidir. Daha az ışığa ihtiyaç duyan bitkiler ikinci grubu oluşturmakla birlikte (örn. Anthurium andraeanum (Antoryum), Begonia spp. (Begonya), Dieffenbachia maculata (Difenbahya) türleri, bu bitkilerin yer seçiminde sürekli güneş ışığı almayan, doğu ve/veya batı cephelerin tercih edilmesi gerekmektedir. Bunların dışında gölge koşullarda büyüme ve gelişmeye devam edebilen iç mekân bitkileri de mevcuttur (örn. Araucaria heterophylla (Salon çamı), Chlorophytum comosum (Kordela), Monstera spp. (Deve tabanı) türleri). Bunların ise kuzey cephelerde, güneş almayan yerlerde bulundurulması uygun olacaktır. Bitkilerin yaşayabilmeleri, gelişebilmeleri için zorunlu olan etmenlerden diğeri ise nispi nem ve sudur. İç mekân bitkileri nem isteklerine göre, yüksek orantılı nem isteyenler ve nem istekleri düşük olan türler olmak üzere iki gruba ayrılabilir. Tropikal kökenli bitkilerin nem ihtiyacı \% 80 'in üzerinde, diğer birçok bitkinin ise \%60-70 civarındadır [39]. Yüksek orantılı nem isteyenlere örnek olarak Fittonia verschaffeltii, Adiantum raddianum (Kadın saçı eğreltisi) verilebilirken, Kalanchoe daigremontiana (Aşkın gözyaşları), Euphorbia obesa nem isteği düşük olan iç mekân bitkilerine örnek olarak verilebilir. Bitkilerin ekolojik isteklerine, büyüme ve gelişme özelliklerine göre uygulanan bakım işlemleri de farklılık göstermektedir. Bitkilerin nem isteklerine uygun sulama rejimi düzenlenmelidir. Bitkiye 
ihtiyacından fazla ya da ihtiyacından az su verilmesi bitkiyi olumsuz etkiler. Genel bir kanı olarak yetiştirme harcının ilk 1-2 cm.si kuru ise sulama işlemi yapılmalıdır. İç mekân bitkilerinin yetiştirme ortamları da bitkinin ihtiyacına göre seçilerek belirlenmesi gerekir. Toprakla birlikte faklı materyaller (torf, perlit, vermikulit vb.) bir araya getirilerek karıştııılmalı ve yetiştirme ortamı oluşturulmalıdır. Bitkilerin büyüme hızlarıyla orantılı olarak saksı değişimi yapılmalı, saksı değişimi esnasında yetiştirme ortamı takviyesi de yapılmaktadır. Bitki türüne göre hazırlanan saksı harcı içinde bulunan besin maddelerinin zamanla tüketilmesi ve sulama ile yıkanması sonucu azalmaktadır. Bu nedenle bitkinin yaşamını sağlıklı şekilde sürdürebilmesi, büyüme ve gelişmesini sağlayabilmesi için ilave besin maddesine gereksinim duyulmaktadır [39,41]. Bitkinin beslenmesinde gerekli olan kimyasal elementleri sağlamak için bitkiye verilen maddelere "gübre" adı verilmektedir [5,41]. Kullanılacak gübrenin Azot $(\mathrm{N})$, Fosfor $(\mathrm{P})$ ve Potasyum (K) miktarları, bitkinin eksikliğine, aktif büyüme dönemine ve mevsime uygun belirlenerek uygulanmalıdır [5]. İç mekân süs bitkilerine uygulanan bir diğer bakım işlemi karşılaşılabilecek birçok hastalık ve zararlı etmenle mücadeledir. Bu gibi etmenlerin ortaya çıkmasına engel olmak, hastalık etmenleri ortaya çıktıktan sonra onlarla mücadele etmekten daha kolay, ekonomik ve yararlıdır [5,41]. $\mathrm{Bu}$ durum sağlanamadığında fiziksel ve kimyasal mücadele işlemlerine başvurulmaktadır. İç mekân bitkilerinin yapraklarının temizlenmesi, saksı değişimi sırasında kırılan ve yaşlanan dalların budanması, yabancı otların temizlenmesi de bitkilere uygulanan diğer bakım uygulamalarıdır.

İç mekân bitkisel tasarımlarının yukarıda bahsedilen tür seçimine, türlerin ekolojik istekleri ve bakım uygulamalarına ek olarak estetik ve işlevsel kaygılarla iç mekân dekorasyonun da bir parçası olması ayrıca önem taşımaktadır. Yatırım maliyetleri göz ardı edilemeyecek kadar fazla olan otellerde yapısal dekorasyon yanında bitkisel materyalin de kullanılması ve uyumu müşteri tercihini yönlendiren unsurlardan biri olarak karşımıza çıkmaktadır. Bitkiler yapısal unsurlarla bir bütün olmakla birlikte ortamdaki oksijen miktarını arttırma ve tozları tutma özellikleriyle de otel iç mekânlarında tercih edilmektedir. Dolayısıyla otellerin giriş, lobi ve bahçelerinde kullanılması yanında kullanıcı odalarında da iç mekân bitkilerine yer verilmektedir. Bu çalışmanın amacı, Antalya ilinde yer alan beş yıldızlı otellerin iç mekânlarında yer alan bitki türleri tercihlerinin, bitkisel tasarım kriterleri açısından değerlendirilmesi ve bakım uygulamalarının belirlenmesidir. Bu kapsamda Türkiye'nin en önemli turizm destinasyonlarının başında gelen Antalya İline bağlı kıyı turizminin gelişmiş olduğu ilçelerde belirlenen otellerde, yerinde yapılan gözlemler ve sorumlu peyzaj mimarlarıyla yapılan görüşmeler ile otellerdeki iç mekan bitkileri değerlendirilmiştir.

\section{MATERYAL VE YÖNTEM}

\section{A. MATERYAL}

Çalışmanın ana materyalini Antalya ilinde Serik-Belek, Aksu-Kundu, Manavgat, Muratpaşa, Konyaaltı, Kemer ilçelerinde yer alan yirmi adet beş yıldızlı otelin lobi, restoran ve koridorlarında ve odalarındaki iç mekan bitkileri oluşturmaktadır (Şekil 1). Otellerin seçilmesinde sezonluk olarak hizmet verenler tercih edilmemiş, otellerin dört mevsim hizmet vermesi belirleyici kriter olmuştur. Bunlar; Serik-Belek bölgesinde beş adet olmak üzere Güral Premier Belek (H1), Sensimar Belek Resort (H2), Belconti Resort Belek (H3), Alva Donna Exclusive Hotel (H4), Letoonia Golf Resort Belek (H5); Aksu-Kundu bölgesinde iki adet olmak üzere Delphin Imperial (H6) ve Royal Wings Otel (H7); Manavgat bölgesinde dört adet olmak üzere Sunrise Resort Hotel (H8), Starlight Resort Hotel (H9), The Sense Deluxe (H10), Kamelya K Club World Holiday (H11); Muratpaşa bölgesinde dört adet olmak üzere The Marmara Otel (H12), Akra Barut Otel (H13), Su Otel (14) ve Kervansaray Hotel (H15); Konyaaltı bölgesinde üç adet olmak üzere Rixos Downtown (H16), Sealife Otel (H17), Porto Bello Otel (H18) ve Kemer bölgesinde iki adet olmak üzere Crystal De Luxe Otel (H19) ve Transatlantik Hotel \& Spa (H20)'dır. 


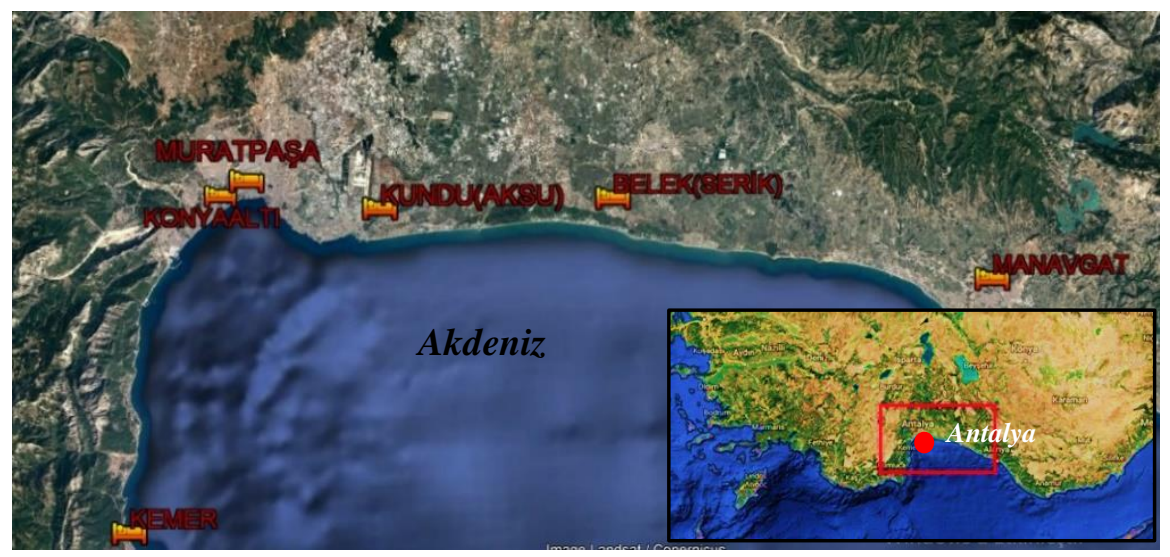

Şekil 1. Çalışma alanı (Google Earth, 2020).

\section{B. YÖNTEM}

Çalışılan otellerde yerinde gözlemler gerçekleştirilerek kullanılan iç mekân bitkileri belirlenmiştir. Otellerin iç mekân bitkilerinden sorumlu kişilerle birebir görüşmeler yapılmıştır. Bilgilerin bir düzen çerçevesinde elde edilmesi için "Bilgi Formu" oluşturulmuş ve her otelde sorumlu kişi ile görüşme esnasında form doldurulmuştur. Elde edilen cevaplar yüzde cinsinden oranlanmış ve oteller genelinde bu yüzdeye göre değerlendirilmiştir. "Bilgi Formu" üç bölümden oluşmaktadır. İlk bölüm 11 adet sorudan oluşmuş olup, otel ile ilgili genel bilgileri, otelde canlı iç mekân bitkisi varlığı, bitkilerle ilgilenen departmanın var olup olmadığı, sorumlu departmanın adı, sorumlu kişinin eğitim durumu, mesleği, mesleki deneyimi, sorumlu olduğu oteldeki hizmet yılı ve departman bünyesinde kaç kişinin görev yaptı̆̆ hakkında bilgileri içermektedir.

Formun ikinci bölümünde, otelin iç mekânında yapılan yerinde gözlemlerin ardından doldurulan 17 adet soruyu içermektedir. Öncelikle otelde iç mekân bitkisinin bulunup bulunmadığı, mevcut ise bulunduğu bölümler (lobi, restoran, koridorlar, odalar) belirlenmiştir. Mevcut bitki türleri teşhis edilerek kayıt altına alınmıştır. İç mekân bitkilerinin işlevlerini, bitki kullanımlarının bitkisel tasarım öğeleri açısından ve bitkisel tasarım ilkeleri açısından derecelendirilerek değerlendirme yapılmıştır. Bitkilerin soliter mi, yoksa bir arada kompozisyon halinde mi kullanıldığ 1 belirlenmiştir. Ayrıca iç mekân bitkilerinin temin durumu, üretim teknikleri, ekolojik isteklerin giderilme yöntemleri hakkında bilgi edinilmiştir.

Formun üçüncü bölümü ise 30 adet sorudan oluşmuş olup iç mekân bitkilerinin bakım uygulamaları ile ilgili sorumlu kişilerden alınan bilgileri sorgulayan soruları içermektedir. En yaygın bakım işlemlerinden sulama (su kaynağı ve miktarı, sulama sıklı̆̆ı), gübreleme (miktarı ve niteliği), saksı değiştirme (sıklığı, zamanı), kurumuş dallar ve yabancı otların bitkiden uzaklaştırılması, budama ve karşılaşılan hastalık ve zararlılar ve mücadele yöntemleri ile ilgili soruları içermektedir.

\section{BULGULAR VE TARTIȘMA}

Elde edilen bulgularda, otellerin tamamının iç mekânlarında bitkilere yer verildiği belirlenmiştir. Tüm otellerin "Bahçe Departmanları" mevcut olup, iç mekân bitkilerinden bu departmanın sorumlu olduğu bildirilmiştir. İç mekân bitkilerinden sorumlu kişiler bu departmanın başında görev yapmakta olup \%60'i Peyzaj Mimarlığı Lisans eğitimi almış, \%25'si Ziraat Mühendisliği Lisans eğitimi almış, \%15’i ise ilköğretim-lise mezunudur. Mesleki deneyimleri ortalama 12 sene olup, görev yaptıkları otellerde ortalama 4 yıldır çalışmakta olduklarını beyan etmişlerdir. Tüm oteller birlikte değerlendirildiğinde ilgili departmanlarda yazın ortalama 26, kışın 14 işçi görev yapmaktadır. Turizm sezonunun yaz aylarına yayılmış olmasından dolayı oteller yaz aylarında en yoğun dönemlerini geçirmekte, kullanıcılar otelde konakladıkları süre boyunca bakımlı ve göze hoş gelen iç mekânlarda zaman geçirmek istemeleri, aynı 
zamanda vejetasyon döneminin yine yaz ayları olmasından dolayı bahçe departmanlarında istihdam edilen işçi sayısının bu dönemde artması beklenen bir durumdur.

Araştırma kapsamında incelenen otel iç mekânlarında tüm otellerin lobi, restoran ve koridorlarında iç mekân bitkisi bulunurken, sadece \%20'sinde (4 otel) kullanıcı odalarında da iç mekân bitkisi bulunduğu belirlenmiştir. İç mekân bitkilerinden sorumlu kişilerle yapılan görüşmeler doğrultusunda otel odalarında iç mekân bitkilerinin bakımının zor olacağını düşündükleri için genellikle odalarda vazo ve restoranlarda kesme çiçek tercih ettiklerini belirtmişlerdir. Tercih edilen kesme çiçek türleri; gül, gerbera, karanfil, hüsnüyusuf, lilyum, antoryum, kadife çiçeği, krizantem olduğunu belirtmişlerdir. Bazı otellerde (H1ve H6) spa girişleri ve kapalı havuz çevresinde de iç mekân bitkileriyle karşılaşılmıştır. Her otelde iç mekân bitkisi ile karşılaşılmış olup tespit edilen tür sayısı otelden otele değişiklik göstermiş̧tir. Tüm oteller birlikte değerlendirildiğinde 42 farklı iç mekân bitki türüyle karşıllaşılmıştır. Bu türlerin otellere göre dağılımı Tablo 1.'de belirtilmiştir.

Otellerde en s1k tercih edilen türlerinin Ficus benjamina, Schefflera actinopylla ve Dypsis lutescens olduğu belirlenmiştir (Şekil 2). Bu türler genel olarak az bakım isteyen, kanaatkar ve maddi değer açısında ekonomik, ayrıca kolay çoğaltılabilen türlerdir. İç mekân bitkilerinin ekolojik isteklerinin (1şık, sıcaklık, nem ve su, yetiştirme ortamı) [5,8,] karşılanmasına ilişkin yapılan gözlemlere göre otel içinde bitkileri konumlandırılmasında sınırlayıcı olan temel faktörün ışı olduğu gözlemlenmiştir. Yapılan sözlü görüşmeler ve gözlemler sonucunda iç mekân bitkilerinin genellikle 1şı alan pencere önlerinde konumlandırıldığı, aksi uygulamaların başarısız bitkisel tasarımlara neden olduğu belirtilmiştir.

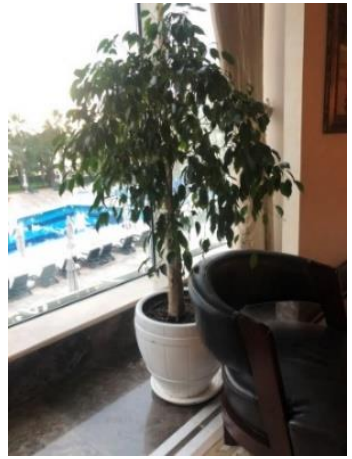

(a)

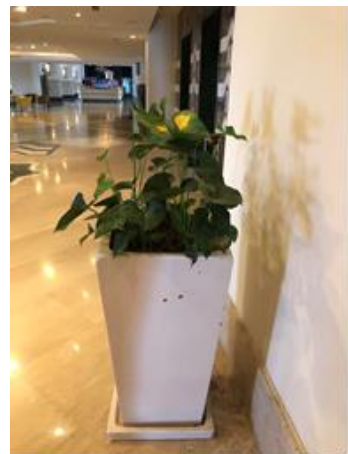

(b)

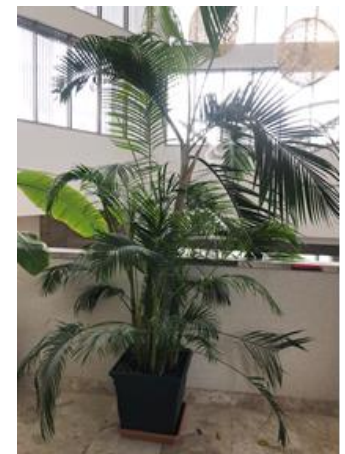

(c)

Şekil 2. Otellerde en çok karşılaşılan iç mekân bitki türleri (a) Kamelya Collection Selin otel lobisinde Ficus benjamin türü. (b) Sunrise otel lobisinde Anthurium andraeanum türü. (c) The Sense otelinin kat koridorunda Dypsis lutescens türü.

Otellerin \%35'inde (7 otel) iç mekân bitkilerinin yanında özellikle restoranlar, odalar, konferans salonları gibi ışık şiddetinin az ve bitki bakımının zor olduğu mekânlarda canlı bitki kullanımı yerine yapay(plastik) bitki kullanımı tercih edildiği gözlemlenmiştir (Şekil 3).

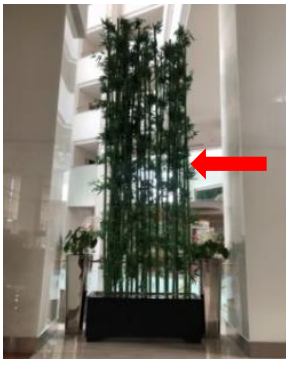

(a)

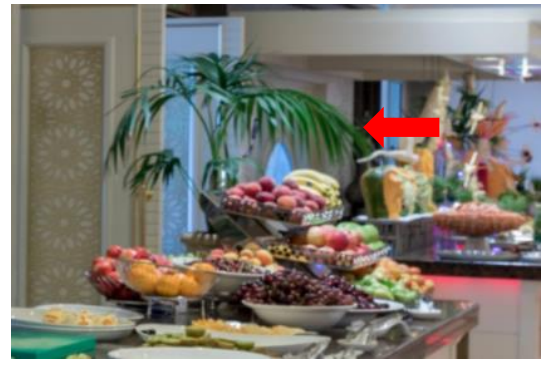

(b)

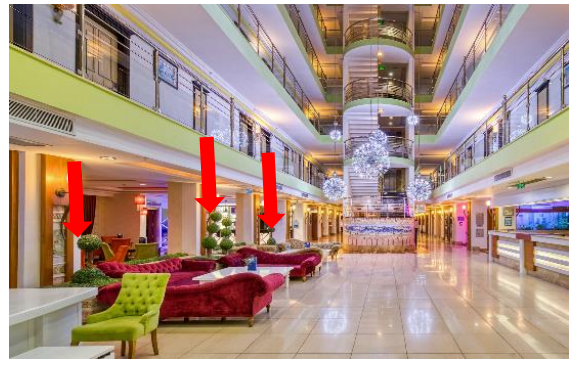

(c)

Şekil 3. Otellerde yapay iç mekân bitkisi kullanımına örnekler (a) The Sense otel lobisindeki yapay bambu (b) Güral Premier Belek restoran bölümünde yapay iç mekân bitkisi kullanımı (c) Sealife Otel Lobisi yapay şimşir kullanımı. 
Tablo 1. Araştırma kapsamında ele alınan otellerde yer alan iç mekân bitkileri türleri.

\begin{tabular}{|c|c|c|c|c|c|c|c|c|c|c|c|c|c|c|c|c|c|c|c|c|c|}
\hline & \multirow[b]{2}{*}{$\begin{array}{c}\text { Tür/Çeşit ismi } \\
\text { (Latince) }\end{array}$} & \multicolumn{20}{|c|}{ Oteller } \\
\hline & & $* \mathbf{H} \mathbf{1}$ & H 2 & H 3 & H4 & H5 & H 6 & H 7 & H 8 & H 9 & H 10 & H 11 & H 12 & H 13 & H 14 & H 15 & H 16 & H 17 & H 18 & H 19 & H 20 \\
\hline 1 & Agave americana & & & & & & & & & & & & & & & & $\mathrm{x}$ & & & & \\
\hline 2 & Anthurium andraeanum & $\mathrm{x}$ & & & $\mathrm{x}$ & $\mathrm{x}$ & & & $\mathrm{x}$ & $\mathrm{x}$ & $\mathrm{x}$ & & & $\mathrm{x}$ & & & & & & & \\
\hline 3 & Aptenia cordifolia & $\mathrm{x}$ & & & & & & & & & & & & & & & & & & & \\
\hline 4 & Bambusa multiplex & & & & $\mathrm{x}$ & & & & & & & & & $\mathrm{x}$ & & & $\mathrm{x}$ & & & & \\
\hline 5 & Calathea makoyana & $\mathrm{x}$ & & & & & & & & & & & & & & & & & & & \\
\hline 6 & Chamaedorea elegans & & & & & & & & & & & & & $\mathrm{x}$ & & & $\mathrm{x}$ & & & & \\
\hline 7 & Chlorophytum comosum & & & & & & & & & & & & & & & & & & & $\mathrm{x}$ & \\
\hline 8 & Citrus mitis & & & & & & & & & & & & & & $\mathrm{x}$ & & & & & & \\
\hline 9 & Cyclamen persicum & & & & & & & & & & & & & & & & $\mathrm{x}$ & & & & \\
\hline 10 & Cycas revoluta & $\mathrm{x}$ & & & & & & & & & & & & & & & & $\mathrm{x}$ & & & \\
\hline 11 & Cyperus alternifolius & & & & & & & & & & & & & & & & $\mathrm{x}$ & & & & \\
\hline 12 & Dieffenbachia maculata & & & & $\mathrm{x}$ & $\mathrm{x}$ & & & & & $\mathrm{x}$ & & & & & & & & & $\mathrm{x}$ & \\
\hline 13 & Dracaena dramensis & & & & $\mathrm{x}$ & $\mathrm{x}$ & & & & & & & & & & & & & & & \\
\hline 14 & Dracaena fragrans & & & & & & $\mathrm{x}$ & & & & $\mathrm{x}$ & & & $\mathrm{x}$ & & $\mathrm{x}$ & & & $\mathrm{x}$ & $\mathrm{x}$ & \\
\hline 15 & Draceana massangena & $\mathrm{x}$ & $\mathrm{x}$ & & $\mathrm{x}$ & & & $\mathrm{x}$ & & & & $\mathrm{x}$ & & & & & & & & & \\
\hline 16 & Draceana marginata & $\mathrm{x}$ & & & & $\mathrm{x}$ & & & & & & $\mathrm{x}$ & & & & & & & $\mathrm{x}$ & & \\
\hline 17 & Dracaena sanderiana & & & & $\mathrm{x}$ & & & & & & & & & & & & & & & & \\
\hline 18 & Draceana bicolor & & $\mathrm{x}$ & & & & & & & & & $\mathrm{x}$ & & & & & & & & & \\
\hline 19 & Dypsis lutescens & & $\mathrm{x}$ & & & & & & & & $\mathrm{x}$ & & $\mathrm{x}$ & $\mathrm{x}$ & & & $\mathrm{x}$ & $\mathrm{x}$ & $\mathrm{x}$ & & \\
\hline 20 & Euphorbia pulcherrima & & & & & & & & & & $\mathrm{x}$ & & & & & & & & & & \\
\hline 21 & Ficus benjamina & & $\mathrm{x}$ & $\mathrm{x}$ & & $\mathrm{x}$ & & & $\mathrm{x}$ & $\mathrm{x}$ & $\mathrm{x}$ & $\mathrm{x}$ & & $\mathrm{x}$ & & $\mathrm{x}$ & & & & & \\
\hline 22 & Ficus binnendiijkii 'Alii' & & & & & & & & $\mathrm{x}$ & $\mathrm{x}$ & & & & & & & & & & & \\
\hline 23 & Ficus elactica & & & & & & & & & & & & & & $\mathrm{x}$ & & & & & & \\
\hline 24 & Ficus lyrata & & & & & & & & $\mathrm{x}$ & $\mathrm{x}$ & $\mathrm{x}$ & $\mathrm{x}$ & & & & & & & & & \\
\hline 25 & Hemionitis arifolia & & & & $\mathrm{x}$ & & & & & & & & & & & & & & & & \\
\hline 26 & Howeia forsteriana & $\mathrm{x}$ & & & & & & & & & & & & & & & $\mathrm{x}$ & $\mathrm{x}$ & & & \\
\hline 27 & Monstera deliciosa & & & & & & & & & & & & & $\mathrm{x}$ & & & & & & & \\
\hline 28 & Musa sp. & $\mathrm{x}$ & & & & & & & & & $\mathrm{x}$ & & & $\mathrm{x}$ & & & $\mathrm{x}$ & & & & \\
\hline
\end{tabular}


Tablo 1 (devam). Araştırma kapsamında ele alınan otellerde yer alan iç mekân bitkileri türleri.

\begin{tabular}{|c|c|c|c|c|c|c|c|c|c|c|c|c|c|c|c|c|c|c|c|c|c|}
\hline & & \multicolumn{20}{|c|}{ Oteller } \\
\hline & & $* \mathbf{H} 1$ & H 2 & H 3 & H 4 & H 5 & H 6 & H 7 & H 8 & H 9 & H 10 & H 11 & H 12 & H 13 & H 14 & H 15 & H 16 & H 17 & H 18 & H 19 & H 20 \\
\hline 29 & Olea europea & & & & & & & & & & & & & & & & & & & & $\mathrm{x}$ \\
\hline 30 & Pelargonium zonale & & & & & & & & & & $\mathrm{x}$ & & & & & & & & & & \\
\hline 31 & Phalaenopsis amabilis & $\mathrm{x}$ & & & & & $\mathrm{x}$ & & & & & & & & & & & & & & \\
\hline 32 & Phoenix dactylifera & & & & & & $\mathrm{x}$ & & & & & & & & & & & & & & \\
\hline 33 & Rhaphidophora aurea & & & & $\mathrm{x}$ & $\mathrm{x}$ & & & & & & & & & & & $\mathrm{x}$ & & & & \\
\hline 34 & Ruellia brittoniana & & & & & & & & & & $\mathrm{x}$ & & & & & & & & & & \\
\hline 35 & Sansevieria trifasciata & $\mathrm{x}$ & & & & & & & & & & & & & & & & & & & \\
\hline 36 & Schefflera actinopylla & & $\mathrm{x}$ & & & $\mathrm{x}$ & & & & & $\mathrm{x}$ & $\mathrm{x}$ & & & & $\mathrm{x}$ & & $\mathrm{x}$ & & & \\
\hline 37 & Scindapsus aureusx & & & & $\mathrm{x}$ & $\mathrm{x}$ & & & $\mathrm{x}$ & $\mathrm{x}$ & & $\mathrm{x}$ & & & & & $\mathrm{x}$ & & & & \\
\hline 38 & Spathiphyllum wallisii & & & & $\mathrm{x}$ & & & & & & & $\mathrm{x}$ & & & & & & & & & \\
\hline 39 & Strelitzia nicolai & $\mathrm{x}$ & & & & & & & & & & & & & & & $\mathrm{x}$ & & & & \\
\hline 40 & Tradescantia pallida & & & & & & & & & & $\mathrm{x}$ & & & & & & & & & & \\
\hline 41 & Yucca spp. & & & & & & & & & & & $\mathrm{x}$ & & & & & $\mathrm{x}$ & & & & \\
\hline 42 & Zamioculcas zamiifolia & $\mathrm{x}$ & & & & & & & & & & & & & & & & & & & \\
\hline
\end{tabular}

* Güral Premier Belek (H1), Sensimar Belek Resort (H2), Belconti Resort Belek (H3), Alva Donna Exclusive Hotel (H4), Letoonia Golf Resort Belek (H5), Delphin Imperial (H6), Royal Wings Otel (H7), Sunrise Resort Hotel (H8), Starlight Resort Hotel (H9), The Sense Deluxe (H10), Kamelya K Club World Holiday (H11), The Marmara Otel (H12), Akra Barut Otel (H13), Su Otel (14), Kervansaray Hotel (H15); Rixos Downtown (H16), Sealife Otel (H17), Porto Bello Otel (H18), Crystal De Luxe Otel (H19), Transatlantik Hotel \& Spa (H20).

Otellerin 17 'sinde(\%85) iç mekân bitkileri saksı içinde kullanılırken, 3 otelde (\%15) bir arada kompozisyon oluşturularak kullanıldığı tespit edilmiştir. Sorumlu kişilerle yapılan sözlü görüşmeler ve gözlemler doğrultusunda otellerde bulunan iç mekân bitkilerinin işlevlerini derecelendirilmiştir. Bu derecelendirme sonucunda otellerde iç mekân bitkisi kullanımlarında en çok estetik(görsel) (ort. 4,7) ve vurgu (ort. 4,3) işlevleri sağlaması için bitki kullanımına yer verildiği belirlenmiştir (Tablo 2). Bitkilerin birçok bilimsel çalışma ile de ortaya konulmuş hava kalitesini iyileştirme, insan psikolojisine olumlu katkı sağlama, iş verimini artırma, sınırlama, yönlendirme işlevlerinin [4,9,13-25,27-34] bitki tercihinde ikinci planda kaldığı anlaşılmıştır. 
Tablo 2. Araş̧tırma kapsamında ele alınan otellerde yer alan iç mekân bitkilerinin işlevlerin, bitkisel tasarım öğeleri ve kriterleri açısından değerlendirilmesi.

\begin{tabular}{|c|c|c|c|c|c|c|c|c|c|c|c|c|c|c|c|c|c|c|c|c|c|}
\hline & \multicolumn{21}{|c|}{ Oteller } \\
\hline & $* \mathbf{H} 1$ & H 2 & H3 & H4 & H 5 & H 6 & H 7 & H 8 & H 9 & H 10 & H 11 & H 12 & H 13 & H 14 & H 15 & H 16 & H 17 & H 18 & H 19 & H 20 & 0 \\
\hline Yapay bitki kullanımı & $\mathrm{x}$ & $\mathrm{x}$ & $\mathrm{x}$ & & & & & & & $\mathrm{x}$ & & & & & & & $\mathrm{x}$ & & $\mathrm{x}$ & $\mathrm{x}$ & \\
\hline \multicolumn{22}{|c|}{ İç mekân bitkilerinin sağladığı işlevler (Derecelerine göre; 1 ; Çok az, 2; az, 3; orta 4; yüksek, 5; çok yüksek) } \\
\hline Estetik (Görsel) & 5 & 5 & 5 & 4 & 5 & 4 & 5 & 5 & 5 & 5 & 4 & 5 & 5 & 5 & 5 & 5 & 4 & 5 & 4 & 4 & 4,7 \\
\hline Sinırlama & 3 & 3 & 2 & 3 & 2 & 3 & 3 & 1 & 3 & 3 & 2 & 3 & 2 & 3 & 3 & 2 & 2 & 3 & 2 & 2 & 2,5 \\
\hline Yönlendirme & 1 & 2 & 3 & 1 & 1 & 1 & 2 & 3 & 1 & 1 & 3 & 2 & 1 & 2 & 2 & 1 & 3 & 1 & 3 & 3 & 1,9 \\
\hline Vurgu & 4 & 4 & 4 & 5 & 4 & 5 & 4 & 4 & 4 & 4 & 5 & 4 & 4 & 4 & 4 & 4 & 5 & 4 & 5 & 5 & 4,3 \\
\hline İç mekân hava kalitesini & 2 & 1 & 1 & 2 & 3 & 2 & 1 & 2 & 2 & 2 & 1 & 1 & 3 & 1 & 1 & 3 & 1 & 2 & 1 & 1 & 17 \\
\hline $\begin{array}{r}\text { İnsan psikolojine olumlu } \\
\text { katkisi }\end{array}$ & 1 & 2 & 3 & 1 & 1 & 2 & 3 & 4 & 4 & 4 & 2 & 2 & 5 & 1 & 2 & 4 & 1 & 2 & 3 & 2 & 2,45 \\
\hline İş verimini arttırma & 1 & 2 & 2 & 2 & 3 & 2 & 1 & 2 & 3 & 2 & 1 & 2 & 4 & 1 & 2 & 4 & 2 & 1 & 2 & 3 & 2.1 \\
\hline
\end{tabular}

Bitkisel Tasarım Öğeleri (Derecelerine göre; 1; Çok az, 2; az, 3; orta 4; yüksek, 5; çok yüksek)

\begin{tabular}{|c|c|c|c|c|c|c|c|c|c|c|c|c|c|c|c|c|c|c|c|c|c|c|}
\hline \multirow{5}{*}{ 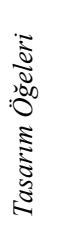 } & Form & 5 & 5 & 5 & 4 & 5 & 5 & 5 & 4 & 5 & 4 & 4 & 5 & 5 & 5 & 5 & 5 & 4 & 5 & 5 & 4 & 4,7 \\
\hline & Çizgi & 4 & 5 & 2 & 3 & 4 & 5 & 4 & 4 & 4 & 5 & 5 & 3 & 3 & 4 & 5 & 5 & 4 & 4 & 4 & 5 & 4,1 \\
\hline & Doku & 4 & 4 & 5 & 3 & 4 & 3 & 3 & 4 & 4 & 2 & 4 & 4 & 3 & 4 & 4 & 5 & 4 & 3 & 3 & 4 & 3,7 \\
\hline & Renk & 3 & 5 & 4 & 5 & 5 & 4 & 4 & 3 & 4 & 3 & 3 & 4 & 4 & 5 & 5 & 5 & 4 & 4 & 5 & 4 & 4,2 \\
\hline & Ölçü & 4 & 4 & 3 & 3 & 4 & 5 & 4 & 4 & 5 & 5 & 4 & 5 & 3 & 4 & 5 & 4 & 4 & 4 & 5 & 5 & 4,2 \\
\hline
\end{tabular}

Bitkisel Tasarım İlkeleri (Derecelerine göre; 1; Çok az, 2; az, 3; orta 4; yüksek, 5; çok yüksek)

\begin{tabular}{|c|c|c|c|c|c|c|c|c|c|c|c|c|c|c|c|c|c|c|c|c|c|}
\hline Vurgu-Odak & 5 & 4 & 5 & 4 & 4 & 5 & 5 & 5 & 4 & 4 & 4 & 5 & 5 & 4 & 3 & 4 & 3 & 4 & 5 & 4 & 43 \\
\hline Ritim-Tekrar & 5 & 4 & 3 & 2 & 3 & 4 & 3 & 4 & 2 & 5 & 4 & 3 & 1 & 4 & 2 & 2 & 3 & 4 & 4 & 3 & 3,25 \\
\hline Denge & 2 & 1 & 3 & 4 & 2 & 1 & 2 & 1 & 1 & 3 & 4 & 4 & 2 & 4 & 1 & 1 & 2 & 4 & 5 & 4 & 2,55 \\
\hline Egemenlik & 3 & 2 & 3 & 3 & 2 & 2 & 1 & 2 & 3 & 4 & 1 & 2 & 2 & 2 & 1 & 1 & 2 & 1 & 1 & 2 & 2 \\
\hline Oran & 5 & 4 & 5 & 4 & 4 & 2 & 4 & 5 & 3 & 4 & 5 & 4 & 2 & 3 & 4 & 4 & 3 & 4 & 3 & 3 & 3,75 \\
\hline Birlik & 1 & 2 & 1 & 3 & 4 & 2 & 2 & 1 & 2 & 3 & 4 & 1 & 3 & 2 & 2 & 3 & 4 & 3 & 1 & 2 & 2,3 \\
\hline Uyum-Zitlık & 4 & 2 & 1 & 3 & 2 & 4 & 1 & 2 & 2 & 3 & 4 & 3 & 3 & 4 & 2 & 2 & 3 & 4 & 2 & 3 & 2,7 \\
\hline Koram-Hiyerarşi & 2 & 1 & 2 & 2 & 2 & 4 & 2 & 3 & 1 & 2 & 2 & 1 & 1 & 1 & 2 & 2 & 1 & 2 & 2 & 1 & \\
\hline
\end{tabular}

* Güral Premier Belek (H1), Sensimar Belek Resort (H2), Belconti Resort Belek (H3), Alva Donna Exclusive Hotel (H4), Letoonia Golf Resort Belek (H5), Delphin Imperial (H6), Royal Wings Otel (H7), Sunrise Resort Hotel (H8), Starlight Resort Hotel (H9), The Sense Deluxe (H10), Kamelya K Club World Holiday (H11), The Marmara Otel (H12), Akra Barut Otel (H13), Su Otel (14), Kervansaray Hotel (H15); Rixos Downtown (H16), Sealife Otel (H17), Porto Bello Otel (H18), Crystal De Luxe Otel (H19), Transatlantik Hotel \& Spa (H2O). 
Otellerde bulunan iç mekân bitkileri bitkisel tasarım öğeleri açısından değerlendirildiğinde bitkilerin sahip oldukları form, çizgi, doku, renk, ölçü özelliklerinden farklı düzeylerde faydalanıldığı belirlenmiştir (Tablo 2). Örneğin; Scindapsus aureusx gibi çizgisel özelliklere sahip sarkıcı bitkiler kullanılan tasarımlarla karşılaşılmış, bitkilerin sahip oldukları renkli çiçekler (Euphorbia pulcherrima, Anthurium andraeanum, Pelargonium zonale gibi) ile odak noktası oluşturulmak istenmiş, kaba dokulu (Ficus lyrata gibi)-ince dokulu (Dypsis lutescens) bitkilere yer verilmiş, otellerin yüksek tavanlı lobilerinde uzun boylu (Howeia forsteriana) bitkilere yer verilerek mekân insan ölçeğine indirgenmeye çalışılmıştır (Şekil 4). Bitkisel tasarım öğelerinin her biri kendi içinde değerlendirildiğinde tüm otellerde kullanılan iç mekân bitkilerinin sağladığ 1 bitkisel tasarım öğeleri sırasıyla form $(4,7)$, renk $(4,2)$ ve ölçü $(4,2)$, çizgi $(4,1)$ ve doku $(3,7)$ şeklindedir.

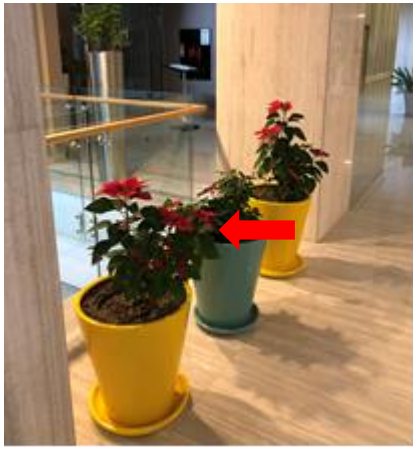

(a)

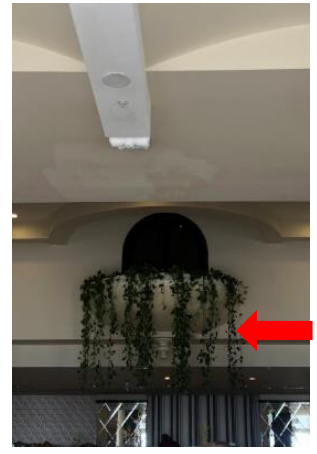

(b)

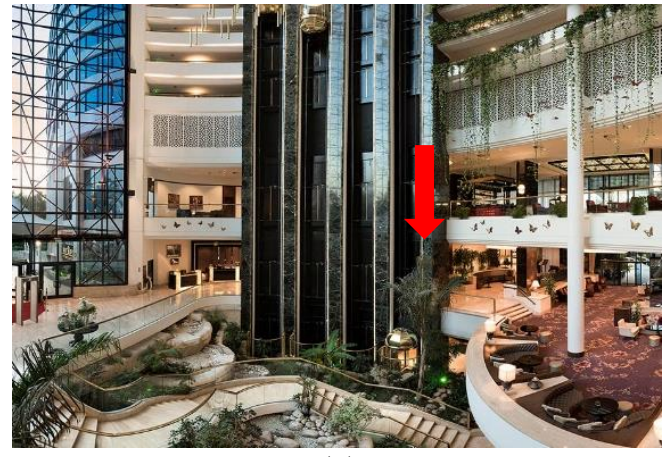

(c)

Şekil 4. Otellerde bulunan iç mekân bitkilerinin bitkisel tasarım öğeleri açısından değerlendirilmesi (a) The

Sense Otelde saksı içinde kullanılan Euphorbia pulcherrima bitkisinin çiçeklerinin renk tasarım öğesinden faydalanılmış (b) Sunrise otelde sarkıcı karakterdeki Scindapsus aureusx bitkisinin çizgisel tasarım öğesinden yararlanılmış (c) Rixos Downtown iç mekânında merdiven boşluklarının oluşturduğu mekânda kullanılan boylu Howeia forsteriana palmiyesinin ölçü tasarım öğesinden faydalanılmış.

Otellerdeki iç mekân bitkileri bitkisel tasarım ilkeleri açısından değerlendirildiğinde; bitki varlığıyla sirasiyla vurgu-odak $(4,3)$, oran $(3,75)$, ritim-tekrar $(3,25)$, uyum-zitlik $(2,7)$, denge $(2,55)$, birlik $(2,3)$, egemenlik (2) ve konum-hiyerarşi $(1,8)$ ilkeleri göz önünde bulundurularak tasarım oluşturulduğu belirlenmiştir (Şekil 10).

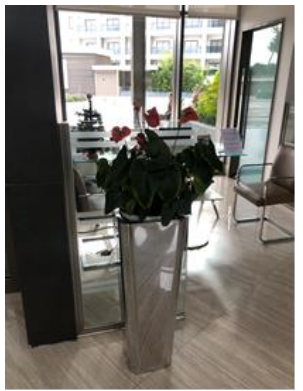

(a)

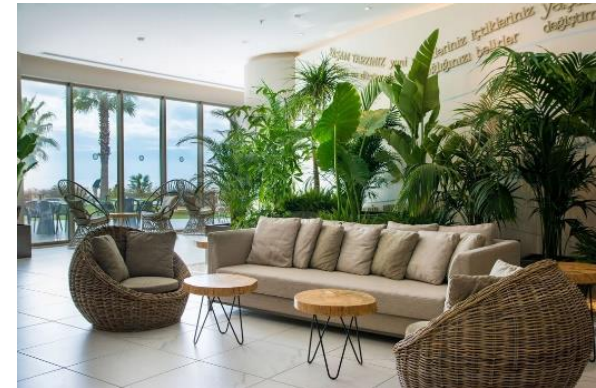

(b)

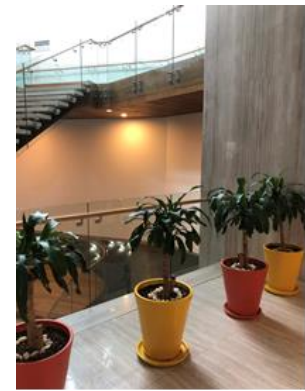

(c)

Şekil 5. Otellerde bulunan iç mekân bitkilerinin bitkisel tasarım ilkeleri açısından değerlendirilmesi (a) The Sense Otel lobisinde metal saksı içinde konumlandırllmış Anthurium andraeanum türü ile oluşturulan bitkisel tasarımda vurgu-odak (b) Akra Barut farklı boylarda bitki grupları kullanılarak gerçekleştirilen bitkisel tasarımda oran (c) The Sense otelinin kat koridorunda Dracaena fragrans türü ile gerçekleştirilen bitkisel tasarımda ritim- tekrar.

İç mekân bitkilerinin temin edilme şekline bakıldığında otellerin \%40’ının (8 otel) kendi bünyesinde üretim serasına sahip olduğu ve çelikle çoğaltım tekniği kullanarak üretim yaptıkları belirlenmiştir. Kullanılan çelik çeşitleri türden türe değişiklik göstermektedir. Otellerde bulunan iç mekân bitkilerinin toprak, plastik, metal, kompozit saksılar içerisinde yer aldığı belirlenmiştir. Farklı materyallerden yapılmış, farklı doku ve renge sahip saksıların kullanımı bitkisel tasarımlara katkı sağlayan bir 
uygulamadır [41]. Saksı içerisinde bulunan bitkilerin yanında üç otelde bitkiler avlu, kaya bahçesi ve parter şeklinde kullanılarak bitkisel tasarımlar gerçekleştirildiği tespit edilmiştir.

İç mekân bitkilerinin bakım uygulamaları ile ilgili alınan bilgilere göre; tüm bitkilere düzenli bakım uygulanmaktadır. En yaygın bakım işlemlerinden sulama genel olarak yaz aylarında daha sık, kış aylarında daha seyrek olarak gerçekleştirilmektedir. Sulama suyu olarak çeşme suyunun yaygın olarak kullanıldığ 1 belirlenmiş olup, iç mekân bitkilerinin sulanmasında suyun niteliğinin önemli bir kriter olduğu bilinen bir gerçektir. Bu doğrultuda bitkilerin sulanmasında eğer çeşme suyu kullanılacak ise kaynamış-soğutulmuş ya da dinlendirilerek bekletilmiş şekilde kullanımı tavsiye edilmektedir [41]. Böylelikle su kireçten arındırılır ve bitkiye zarar vermez. Otellerde yapılan sulama işlemi bu yönüyle eksik bir uygulama olduğu tespit edilmiştir. Otellerde uygulanan bir diğer bakım işlemi olan gübrelemenin bitkilerin aktif büyüdükleri vejetasyon döneminde (yaz) ayda ortalama 1-2 kere, genellikle azot ağırlıklı gübreler ile yapıldığı belirlenmiştir. Bu kapsamda yapılan gübrelemelerin dönem ve sıklığının doğru olduğu belirlenmekle birlikte, bitkilerde besin elementi eksikliklerini gösterir semptomların takip edilmesi, bitkilerin eksikliklerini gidermeye yönelik bir gübreleme planı yapılması ve uygulanması sürdürülebilir bitkisel tasarımlar açısından daha doğru bir uygulama olacaktır [39, 41]. Bitkilerin gelişimlerini etkileyen bir diğer faktör olan yetiştirme ortamları açısından değerlendirildiğinde genel olarak bahçe toprağı, torf, perlit, vermikülit karışımlarının kullanıldığı tespit edilmiştir. Otellerin \%85'inde saksı değişimi ilkbahar ve sonbahar aylarında yapıldığı belirlenmiştir. Saksı değişim zamanları türlere göre değişmekle birlikte bu işlemin bahar aylarında yapılması uygun bir uygulamadır [41]. Ayrıca kurumuş dallar/yaprakların, yabancı otların temizliğinin de rutin olarak yapıldı ̆̆ı, bu uygulamanın da uygunluğu belirlenmiştir. İç mekân bitkilerinde görülen ve sıklıkla rastlanan hastalık ve zararlıların genel olarak mantar hastalıkları, yaprak bitleri ve kırmızı örümcek olduğu belirtilmiştir. $\mathrm{Bu}$ hastalık ve zararlıların mücadelesinde kullanılan yöntemlerde ise sıklıkla insektisit, fungusit gibi kimyasal ilaç uygulamaları şeklinde olduğu tespit edilmiştir. Oysaki bu gibi etmenlerin ortaya çıkmasına engel olmak, hastalık etmenleri ortaya çıktıktan sonra onlarla mücadele etmekten daha kolay, ekonomik ve yararlı olduğu bilinen bir gerçektir [5,41]. Bu durum sağlanamadığında kimyasal mücadele işlemlerine başvurulması gerektiği bilinciyle uygun bakım işleminin yapılması daha doğru bir uygulama olacaktır.

\section{IV.SONUC}

Türkiye'nin en önemli turizm destinasyonlarının başında gelen ve çalışma alanı olarak belirlenen Antalya İli otellerindeki iç mekân bitkileri, bitkisel tasarım kriterleri kapsamında değerlendirilmiş ve bu otellerin bitkisel tasarımlarından sorunlu kişilerin çoğunlukla bitki bilgisine sahip uzmanlar (peyzaj mimarı, ziraat mühendisi) tarafindan yönetildiği bulgusu ile yapılan tasarımların olumlu olduğu anlaşılmıştır. Bu uzmanların otellerdeki varlığı, bitkilerin kullanım, bakım ve işlevselliğini büyük oranda etkilemiş, bitkisel tasarım kriterlerinin uygulandığı sonucuna ulaşılmıştır. Ancak, ekonomik kaygılar ve bakım zorlukları, tür seçiminde genellikle az bakım isteyen ve sık kullanılan ekonomik bitkilerin seçildiğini göstermiştir. Dolayısıyla, iç mekânda arzu edilen işlevi ve estetiği sağlaması için seçilmesi gereken bitkiler, ekonomik kaygilar neticesinde çeşitlenememiş ve tür çeşitliliği genel olarak kısıtlı kalmıştır. Bunun yanında, bitki tercihlerinde, bitkilerin hava kalitesini iyileştirme, insan psikolojisine olumlu katkı sağlama, iş verimini artırma, sınırlama, yönlendirme işlevlerinin ön plana çıkmadığı anlaşılmıştır. Genellikle estetik özellikleri ve görünüşleri, tür seçiminde en etkili faktör olmuştur. Sulama ve bakım faaliyetleri için ise, eldeki imkanların kullanılması, bu otellerdeki çoğu bitkisel materyalin istenilen form, doku ve renge yeterince ulaşamamasına ve istenilen işlevi tam anlamıla yerine getirememesine sebep olmuştur.

Otellerde kullanılan iç mekân bitkilerinin sürdürülebilir kullanımının sağlanması, öncelikle bitkisel tasarımların uzman kişilerce yapılmasına ve bakım gerekliliklerinin yerine getirilmesine bağlıdır. Bitkisel tasarımlar, ilgili yapıların tasarımlarının yapılması aşamasında sisteme dahil olmalı ve birlikte planlanmalıdır. Yapıların, bitkisel materyaller düşünülmeden tamamlanması, bitkilerin kullanımı aşamasında, 1şık, gölge, sıcaklık, nem vb. sorunları doğurmakta ve bu sorunlar kullanılan bitkilerin 
istenilen işleve ulaşamamasına neden olmaktadır. Otellerde yapılan incelemelerde ve görüşmelerde, bu sorun sıklıkla göze çarpmıştır. Buna rağmen, bitkisel materyalin iç mekanlarda tercih edilmesinin kullanıcı üzerindeki olumlu etkisi bilindiğinden, çalışma kapsamındaki otellerin tamamında iç mekân bitkilerinin kullanıldığı ve bu bitkilerin sahip oldukları tasarım öğeleri ile bir ve birkaç tasarım kriterine uygun yerleştirildiği sonucuna varılmıştır.

\section{KAYNAKLAR}

[1] C. Brod, Technostress: The Human Cost of The Computer Revolution, Reading, USA: AddisonWesley Publishing Company, 1984.

[2] M. S. Lee, J. Lee, B. J. Park and Y. Miyazaki, "Interaction with indoor plants may reduce psychological and physiological stress by suppressing autonomic nervous system activity in young adults: A randomized crossover study," Journal of physiological anthropology, vol. 34, no. 21, pp. 16,2015 .

[3] G. H. Manaker, Interior Plantscapes: Installation, Maintenance, and Management, Englewood Cliffs, NJ: Prentice-Hall, 1996.

[4] T. Bringslimark, T. Hartig and G.G. Patil, "The psychological benefits of indoor plants: A critical review of the experimental literature," Journal of Environmental Psychology, vol. 29, no. 4, pp. 422-433, 2009.

[5] C. Selim, İ. Akgün ve R. Olgun, "Ofislerde kullanılan iç mekân bitki tercihlerinin, bakım olanaklarının ve hava kalitesi üzerine etkilerinin değerlendirilmesi: Akdeniz Üniversitesi örneği," Türk Tarım-Gıda Bilim ve Teknoloji Dergisi, c. 8, s. 3, ss. 702-715, 2020.

[6] Ö.L. Çorbacı, D. Duran Gökalp ve P. Göker, "İç mekânda bitkilerle tasarımda 1şı̆̆ın önemi," Ĕ̈itim Odağında Artvin Sempozyumu, Artvin, Türkiye, 2012, ss. 211-222.

[7] H. Çelem, M. Arslan, İç Mekân Bitkileri, Ankara, Türkiye: Tagey Yayıncılık, 1995.

[8] I. Sezen, B. Aytatlı, R. Ağrılı ve E. Patan, "İç mekân tasarımında bitki kullanımının birey ve mekân üzerine etkileri,” ATA Planlama ve Tasartm Dergisi, c. 1, s.1, ss. 25-34, 2017.

[9] L. Deng, Q. Deng, "The basic roles of indoor plants in human health and comfort," Environ. Sci. Pollut. Res., vol. 25, pp. 36087-36101, 2018.

[10] G. P. Bot, "Developments in indoor sustainable plant production with emphasis on energy saving," Comput. Electron. Agric., vol 30, pp. 151-165, 2001.

[11] J. Messinger, G. Renger, "Photosynthetic water splitting," in Primary Processes of Photosynthesis, Part 2: Principles and Apparatus, Cambridge, UK: RSC Publishing, 2008, pp. 291351.

[12] X. Yan, H. Wang, Z. Hou, S. Wang, D. Zhang, Q. Xu and T. Tokola, "Spatial analysis of the ecological effects of negative air ions in urban vegetated areas: A case study in Maiji, China," Urban For Urban Green, vol. 14, pp. 636-645, 2015.

[13] A. R. Khan, A. Younis, A. Riaz and M. M. Abbas, "Effect of interior plantscaping on indoor academic environment," Journal of Agriculture Research, vol. 43, pp. 235-242, 2005. 
[14] F. Korte, G. Kvesitadze, D. Ugrekhelidze, M. Gordeziani, G. Khatisashvili, O. Buadze and G. Zaalishvili, "Organic toxicants and plants," Ecotoxicol. Environ. Saf., vol. 47, no.1, pp. 1-26, 2000.

[15] B. Guieysse, C. Hort, V. Platel, R. Munoz, M. Ondarts and S. Revah, "Biological treatment of indoor air for VOC removal: potential and challenges," Biotechnology Advances, vol. 26, pp. 398-410, 2008.

[16] B. C. Wolverton, A. Johnson and K. Bounds. (1989, September 15). Interior landscape plants for indoor air pollution abatement [Online]. Available: https://ntrs.nasa.gov/api/citations/19930073077/downloads/19930073077.pdf

[17] G. A. Beattie, J. R. Seibel, "Uptake and localization of gaseous phenol and p-cresol in plant leaves," Chemosphere, vol. 68, pp. 528-536, 2007.

[18] R. L. Orwel, R. L. Wood, J. Tarran, F. Torpy and M. D. Burchett, "Removal of benzene by the indoor plant/substrate microcosm and implications for air quality," Water Air Soil Pollut., vol. 157, pp. 193-207, 2004.

[19] Y. J. Liu, Y. J. Mu, Y. G. Zhu, H. Ding and N. C. Arens, "Which ornamental plant species effectively remove benzene from indoor air?," Atmos. Environ., vol. 41, pp. 650-654, 2007.

[20] H. Şevik, M. Çetin ve K. Işı̧nkaralar, "Bazı iç mekân süs bitkilerinin kapalı mekânlarda karbondioksit miktarına etkisi," Düzce Üniversitesi Bilim ve Teknoloji Dergisi, c. 4, ss. 493-500, 2016.

[21] L. Pastore, R. Corrao and P. K. Heiselberg, "The effects of vegetation on indoor thermal comfort: The application of a multi-scale simulation methodology on residential neighborhood renovation case study," Interdisciplinary Energy and Buildings, vol. 146, pp. 1-11, 2017.

[22] K. Dijkstra, M. E. Pieterse and A. Pruyn, "Stress reducing effects of indoor plants in the built healthcare environment: The mediating role of perceived attractiveness," Preventive Medicine, vol. 47, pp. 279-283, 2008.

[23] T. Fjeld, B. Veiersted, L. Sandvik, G. Riise and F. Levy, "The effect of indoor foliage plants on health and discomfort symptoms among office workers," Indoor Built Environ., vol. 7, pp. 204-209, 1998.

[24] K. T. Han, "Influence of limitedly visible leafy indoor plants on the psychology, behavior and health of students at a junior high school in Taiwan," Environ. Behav., vol. 41, pp. 658-692, 2009.

[25] Z. Xu, L. Wang and H. Hou, "Formaldehyde removal by potted plant-soil systems," J. Hazard Mater., vol. 192, pp. 314-318, 2011.

[26] C. A. Shoemaker, P. D. Relf and V. I. Lohr, "Social science methodologies for studying individuals' responses in human issues in horticulture research," HortTechnology, vol. 10, pp. 87-93, 2010.

[27] R.K. Ranaas, K. Horgen Evensen, D. Rich, G. Sjøstrøm, G. Patil, "Benefits of indoor plants on attention capacity in an office setting," Journal of Environmental Psychology, vol. 31, pp. 99-105, 2011.

[28] T. Fjeld, "The effect of interior planting on health and discomfort among workers and school children," HortTechnology, vol. 10, pp. 46-52, 2000.

[29] V. I. Lohr, C. H. Pearson-Mims, "Physical discomfort may be reduced in the presence of interior plants," HortTechnology, vol. 10, pp. 53-58, 2000. 
[30] S. Shibata, N. Suzuki, "Effects of indoor foliage plants on subjects' recovery from mental fatigue," Journal of Psychology, vol. 3, pp. 385-396, 2001.

[31] S. Shibata, N. Suzuki, "Effects of the foliage plant on task performance and mood," Journal of Environmental Psychology, vol. 22, pp. 265-272, 2002.

[32] E. Kim, R. H. Mattson, "Stress recovery effects of viewing red-flowering geraniums," Journal of Therapeutic Horticulture, vol. 13, pp. 4-12, 2002.

[33] M. Liu, E. Kim and R. H. Mattson, "Physiological and emotional influences of cut flower arrangement and lavender fragrance on university students," Journal of Therapeutic Horticulture, vol. 14, pp. 18-27, 2003.

[34] S. Shibata, N. Suzuki, "Effects of an indoor plant on creative task performance and mood," Scandinavian Journal of Psychology, vol. 45, pp. 373-381, 2004.

[35] S. H. Park, R. H. Mattson and E. Kim, "Pain tolerance effects of ornamental plants in a simulated hospital patient room," Acta Horticulturae, vol. 639, pp. 241-247, 2004.

[36] S. H. Park, R. H. Mattson, "Therapeutic influences of plants in hospital rooms on surgical recovery," HortScience, vol. 44, pp. 1-4, 2009.

[37] S. H. Park, R. H. Mattson, "Effects of flowering and foliage plants in hospital rooms on patients recovering from abdominal surgery," HortTechnology, vol. 18, pp. 563-568, 2008.

[38] A. Esentürk, Ö. Yerli, "Peyzaj tasarımında yeni bir bitki yetiştirme sanatı: Kokedama,” Düzce Üniversitesi Bilim ve Teknoloji Dergisi, c. 7, ss. 1858-1866, 2019.

[39] Z. Dilaver. (2019, 24 Nisan). Iç mekân bitkileri ve tasarımı [Online]. Available: https://acikders.ankara.edu.tr/course/view.php?id=5473,\%202019.

[40] A. Ulus, "Bazı iç mekân bitkilerinin kullanım tekniği üzerine çalışmalar," İstanbul Üniversitesi Orman Fakültesi Dergisi, c. 56, s. 2, ss. 146-161, 2006.

[41] N. Oral, İç Mekân Süs Bitkileri Özelikleri, Üretimi ve Bakımı, Yalova, Türkiye: Tarımsal Araştırmaları Destekleme ve Geliştirme Vakfı, 1987. 